\title{
Synthesis of D-manno-heptulose via a cascade aldol/hemiketalization reaction
}

\author{
Yan Chen, Xiaoman Wang, Junchang Wang and You Yang *
}

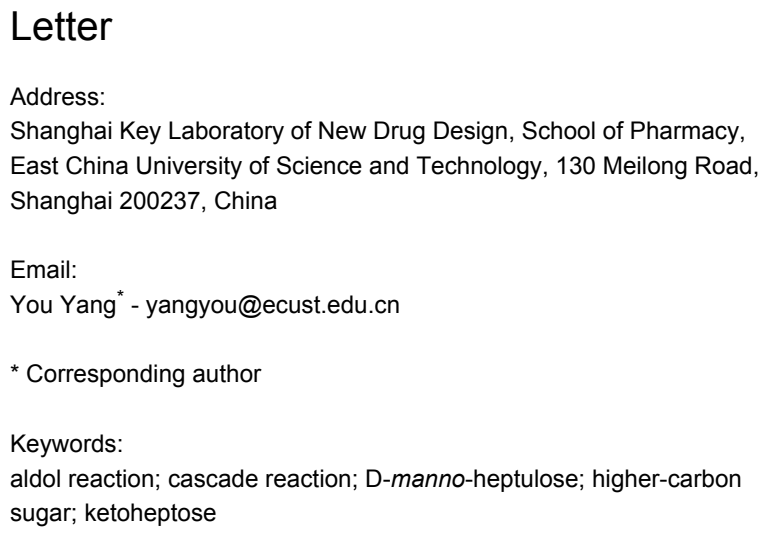

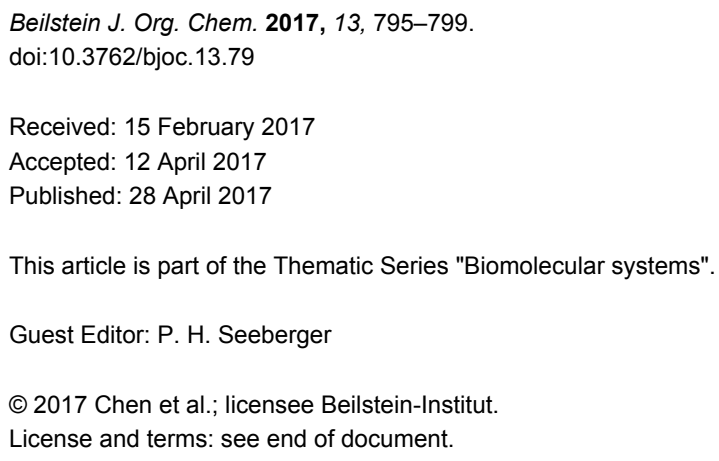

\begin{abstract}
$\mathrm{A}[4+3]$ synthesis of D-manno-heptulose is described. The cascade aldol/hemiketalization reaction of a $\mathrm{C}_{4}$ aldehyde with a $\mathrm{C}_{3} \mathrm{ke-}$ tone provides the differentially protected ketoheptose building block, which can be further reacted to furnish target D-manno-heptulose.
\end{abstract}

\section{Introduction}

D-manno-Heptulose is a rare naturally occurring seven-carbon sugar first isolated from avocado [1], which exhibited promising diabetogenic effects through suppression of the glucose metabolism and insulin secretion via competitive inhibition of the glucokinase pathway [2-6]. Accordingly, ketoheptoses and fluorinated ketoheptoses were considered to be potential therapeutic agents for hypoglycemia and cancer as well as diagnostic tools for diabetes [7-12]. Amino- and azido-group-containing ketoheptoses were also synthesized for the development of novel antibiotics and the evaluation of carbohydrate-lectin interactions by conjugation with fluorescent quantum dots via click chemistry $[13,14]$. Besides, differentially protected D-manno-heptulose building blocks could serve as valuable precursors for the synthesis of $C$-glycosides $[15,16]$.
The known synthesis of D-manno-heptulose mainly rely on the use of rearrangements and chain elongation reactions [17]. Rearrangement reactions such as the Lobry de Bruyn rearrangement and the Bilik rearrangement employ unprotected aldoses as substrates, usually yielding an equilibrium mixture of aldoses and ketoses $[18,19]$. In addition to chain elongations of aldoses employing the Henry reaction, the aldol reaction, and the Wittig reaction for the preparation of ketoheptoses [20-22], sugar lactones were also often utilized for the synthesis of D-mannoheptulose via reactions with $C$-nucleophiles or conversion into exocyclic glycals followed by dihydroxylation [10-13,23-27]. Remarkably, Thiem et al. reported the highly efficient synthesis of D-manno-heptulose from D-mannose in 59\% overall yield over five steps [26]. However, the synthesis of D-manno-heptu- 
lose and its derivatives from the common differentially protected ketoheptose building block is still attractive due to the versatile functionalization possibilities of the building block into various derivatives of D-manno-heptulose. A de novo synthesis has proved to be an attractive strategy to produce orthogonally protected carbohydrate building blocks from simple precursors [28-39]. Here, we report a [4+3] approach to access differentially protected ketoheptose building blocks, which enables the synthesis of D-manno-heptulose. As depicted in Scheme 1, D-manno-heptulose (1) could be obtained by global deprotection of the differentially protected ketoheptose building block 2. The ketoheptose 2 can be further divided into $\mathrm{C}_{4}$ aldehyde 3 and $\mathrm{C}_{3}$ ketone $\mathbf{4}$ via a cascade aldol/hemiketalization pathway.

\section{Results and Discussion}

The synthesis of the $\mathrm{C}_{4}$ aldehyde commenced with commercially available D-lyxose (5, Scheme 2$)$. The reaction of $\mathbf{5}$ with ethanethiol in the presence of hydrochloric acid followed by selective protection of the 4,5-diol with 2,2-dimethoxypropane using pyridinium $p$-toluenesulfonate as the promoter gave the 4,5-O-isopropylidene derivative 6 in 71\% yield over two steps [40]. Treatment of diol 6 with bis(tributyltin) oxide and subsequent exposure to $p$-methoxybenzyl (PMB) chloride in the presence of tetra- $n$-butylammonium bromide (TBAB) at $110{ }^{\circ} \mathrm{C}$ led to regioselective protection of the 3-OH with the $\mathrm{PMB}$ group, affording the 3-O-PMB protected alcohol 7 (55\%) [41]. At this stage, we initially planned to synthesize the 2-OH-protected $\mathrm{C}_{4}$ aldehyde for the assembly of the seven-carbon skeleton. Thus, acetylation of the 2-OH group in 7 with acetic anhydride and DMAP in dichloromethane provided ester 8 in $86 \%$ yield. The positions of the 2-acetyl and 3-PMB groups were determined by ${ }^{1} \mathrm{H},{ }^{13} \mathrm{C}$ and 2D NMR spectra of $\mathbf{8}$ (see Supporting Information File 1 for details). Cleavage of the isopropylidene acetal group in 8 under acidic conditions gave diol 9 (50\%). However, oxidative cleavage of diol 9 with sodium periodate resulted in the unexpected formation of $\alpha, \beta$-unsaturated aldehyde $\mathbf{1 0}$ in $71 \%$ yield, indicating that the 2 -acetyl group might be prone to initiate the elimination reaction. The double bond of $\mathbf{1 0}$ was assigned to have $Z$-configuration based on the analysis of the NOEs between the olefinic hydrogen and the aldehyde hydrogen (see Supporting Information File 1 for details). In addition, when alcohol 7 was subjected to benzoyl chloride and DMAP in dichloromethane at room temperature or tert-butyldimethylsilyl chloride and imidazole in DMF at room temperature, no reaction occurred probably because of the steric hindrance between the 2-OH group and the surrounding functional groups.

To overcome the difficulties in the synthesis of the 2-OH-protected $\mathrm{C}_{4}$ aldehyde and to improve the synthetic efficiency in
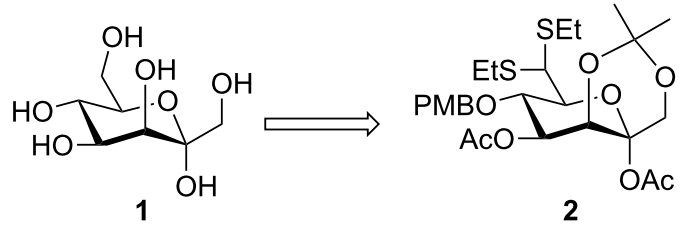

2

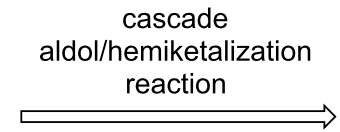

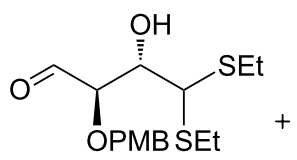

3<smiles>CC1(C)OCC(=O)CO1</smiles>

4

Scheme 1: Retrosynthetic analysis of D-manno-heptulose.

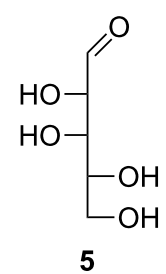

1. EtSH, aq $\mathrm{HCl}, 0{ }^{\circ} \mathrm{C}$ to $\mathrm{rt}$

2. 2,2-dimethoxypropane, pyridinium $p$-toluenesulfonate, acetone, $\mathrm{rt}$

$71 \%$ over two steps

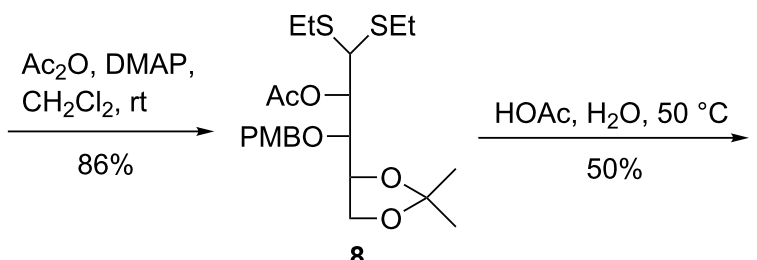

8
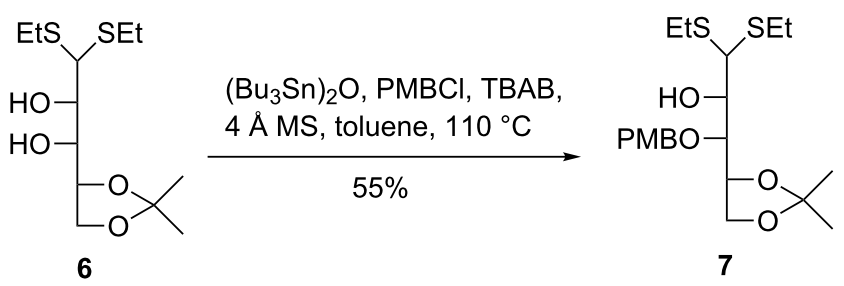

7

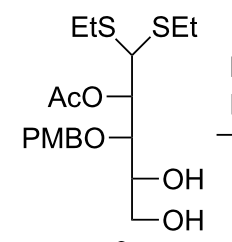

9
$\mathrm{NaIO}_{4}, \mathrm{THF}$,<smiles>[H][R16]([H])(CC)OC(C=O)=CC([SiH2]CC)[Sb]O</smiles>

10 
the assembly of ketoheptose skeletons, we envisioned ketoheptoses could be assembled by a cascade aldol/hemiketalization reaction between 2-OH-unprotected $\mathrm{C}_{4}$ aldehyde 3 and $\mathrm{C}_{3}$ ketone 4. As such, the isopropylidene acetal group in 7 was cleaved under acidic conditions to produce triol 11 in $86 \%$ yield (Scheme 3). Cleavage of the resulting vicinal diol in $\mathbf{1 1}$ with sodium periodate led to the $\mathrm{C}_{4}$ aldehyde 3 in nearly $60-70 \%$ yield. In this oxidative cleavage reaction, almost no elimination product was found based on TLC monitoring. Given that the $\mathrm{C}_{4}$ aldehyde 3 was unstable upon purification by silica gel column chromatography, it was immediately used for the subsequent coupling after the extraction procedure. The aldol reaction of aldehyde 3 with the readily available ketone $4[42,43]$ under the catalysis of L-proline at room temperature for three days proceeded sluggishly, leading to the desired product in a very low yield. Gratifyingly, when the L-proline-catalyzed aldol reaction was performed at $70{ }^{\circ} \mathrm{C}$ for one day, the TLC indicated the complete consumption of aldehyde 3 , and the generated 4,5-anti-selective coupling intermediate $\mathbf{1 2}$ underwent in situ cyclization to provide hemiketal $\mathbf{1 3}$ as the major product in about $50-60 \%$ yield ( $35 \%$ overall yield from compound 11 ). Notably, trace amounts of a stereoisomer and a minor highly polar unknown byproduct were also observed in this cascade reaction. The excellent anti-selectivity for the L-proline-catalyzed aldol reaction can be explained by the Houk-List transition state model [43-45]. Compound $\mathbf{1 3}$ was then acetylated to afford differentially protected ketoheptose building block $\mathbf{2}$ in $83 \%$ yield. The structure of 2 was unambiguously confirmed by ${ }^{1} \mathrm{H},{ }^{13} \mathrm{C}$, and 2D NMR spectra (see Supporting Information File 1 for details). The anomeric $\alpha$-configuration of compound 2 was confirmed by analysis of the NOE effects between the C-1 hydrogen and the C-5 hydrogen.

With the ketoheptose building block 2 in hand, we turned our attention to the synthesis of D-manno-heptulose (1). Upon exposure to NBS in acetonitrile and water, the dithioacetal in $\mathbf{2}$ was cleaved to give the corresponding aldehyde [46,47], which was then reduced by potassium borohydride in a methanol and dichloromethane solvent mixture to produce alcohol $\mathbf{1 4}$ as the predominant product ( $84 \%$ over two steps, Scheme 4$)$. In addition, a trace amount of the deacetylated product was also detected . DDQ-mediated oxidative cleavage of the PMB group in alcohol 14 produced only a moderate yield $(\approx 50 \%)$ of the 5,7-diol probably due to the presence of the free 7-hydroxy group. We envisaged that protection of the free 7-hydroxy group in $\mathbf{1 4}$ followed by treatment with DDQ could yield the desired 5-hydroxy product in high yield. Indeed, acetylation of alcohol 14 with acetic anhydride delivered ester 15 in $91 \%$ yield. Removal of the PMB group in 15 with DDQ resulted in a very clean reaction, affording alcohol $\mathbf{1 6}$ in an excellent yield (91\%). Saponification of all esters in $\mathbf{1 6}$ with potassium carbonate followed by acidic cleavage of the isopropylidene
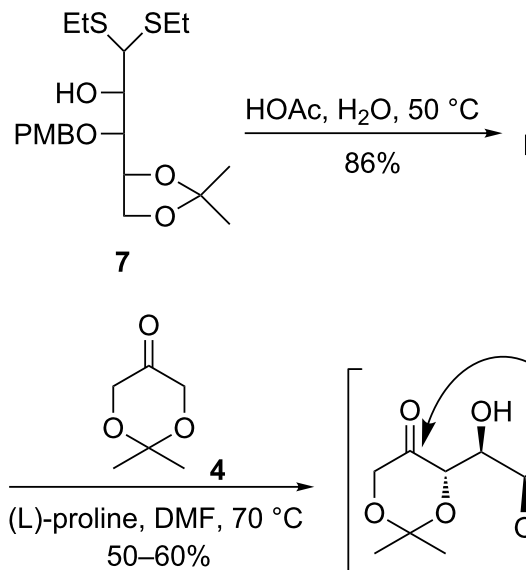

$50-60 \%$

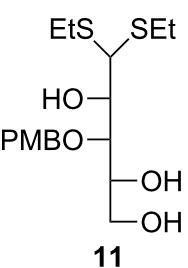

11<smiles>CCC(CC)C(O)C(C=O)OCCO[N+](=O)[O-]</smiles>

3

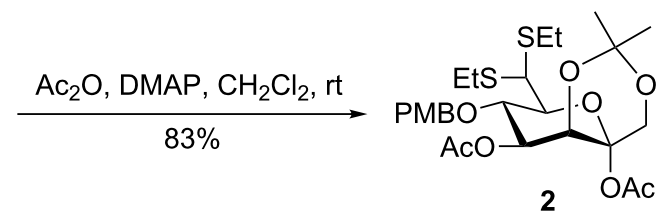



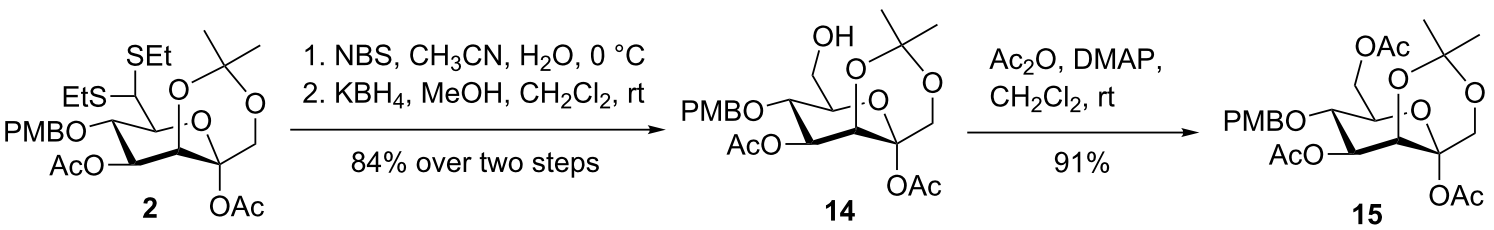

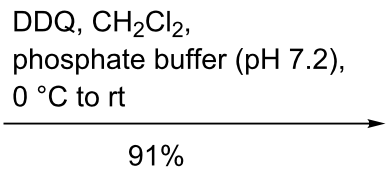

phosphate buffer ( $\mathrm{pH} 7.2)$ $91 \%$

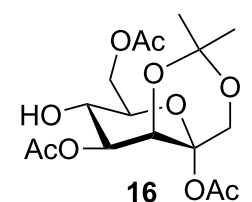

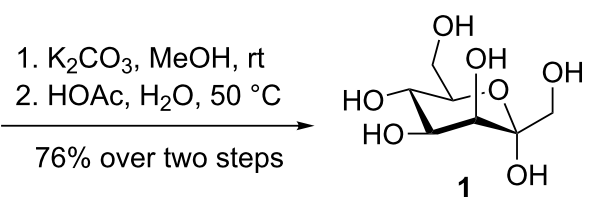

Scheme 4: Synthesis of D-manno-heptulose (1).

acetal group with aqueous acetic acid furnished D-mannoheptulose $(\mathbf{1}, 76 \%$ over two steps). The structure of $\mathbf{1}$ was found to be in good agreement with those reported for $\alpha$-D-mannoheptulose (1) by comparison of the NMR spectra (see Supporting Information File 1 for details) [26].

\section{Conclusion}

In summary, we have described a [4 + 3] approach for the synthesis of D-manno-heptulose (1) starting from D-lyxose (5). The key step is a cascade aldol/hemiketalization reaction for the construction of the differentially protected ketoheptose building block, which was finally converted into D-manno-heptulose for subsequent biological evaluation. Although the synthesis of D-manno-heptulose ( $5 \%$ overall yield, 13 steps) is not so efficient as the Thiem's method (59\% overall yield, 5 steps), the reported differentially protected ketoheptose building blocks may find further application in the preparation of structurally diverse D-manno-heptulose derivatives.

\section{Supporting Information}

\section{Supporting Information File 1}

Experimental details, characterization data, and NMR spectra of all new compounds.

[http://www.beilstein-journals.org/bjoc/content/ supplementary/1860-5397-13-79-S1.pdf]

\section{Acknowledgements}

Financial support from the National Thousand Young Talents Program (YC0130518, YC0140103), the Shanghai Pujiang Program (15PJ1401500), the Fundamental Research Funds for the Central Universities (WY1514052), and the Opening Project of State Key Laboratory of Bio-organic and Natural Products Chemistry (Y100-D-1501) is gratefully acknowledged.

\section{References}

1. La Forge, F. B. J. Biol. Chem. 1917, 28, 511-522.

2. Roe, J. H.; Hudson, C. S. J. Biol. Chem. 1936, 112, 443-449.

3. Simon, E.; Kraicer, P. F. Arch. Biochem. Biophys. 1957, 69, 592-601. doi:10.1016/0003-9861(57)90523-4

4. Paulsen, E. P.; Richenderfer, L.; Winick, P. Nature 1967, 214, 276-277. doi:10.1038/214276b0

5. Coore, H. G.; Randle, P. J. Biochem. J. 1964, 91, 56-59. doi:10.1042/bj0910056

6. Zelent, D.; Najafi, H.; Odili, S.; Buettger, C.; Weik-Collins, H.; Li, C.; Doliba, N.; Grimsby, J.; Matschinsky, F. M. Biochem. Soc. Trans. 2005, 33, 306-310. doi:10.1042/BST0330306

7. Paulsen, E. P. Ann. N. Y. Acad. Sci. 1968, 150, 455-456. doi:10.1111/j.1749-6632.1968.tb19069.x

8. Board, M.; Colquhoun, A.; Newsholme, E. A. Cancer Res. 1995, 55, 3278-3285.

9. Malaisse, W. J. Diabetologia 2001, 44, 393-406. doi:10.1007/s001250051635

10. Leshch, Y.; Waschke, D.; Thimm, J.; Thiem, J. Synthesis 2011, 3871-3877. doi:10.1055/s-0031-1289598

11. Waschke, D.; Leshch, Y.; Thimm, J.; Himmelreich, U.; Thiem, J. Eur. J. Org. Chem. 2012, 948-959. doi:10.1002/ejoc.201101238

12. Malaisse, W. J.; Zhang, Y.; Louchami, K.; Sharma, S.; Dresselaers, T.; Himmelreich, U.; Novotny, G. W.; Mandrup-Poulsen, T.; Waschke, D.; Leshch, Y.; Thimm, J.; Thiem, J.; Sener, A. Arch. Biochem. Biophys. 2012, 517, 138-143. doi:10.1016/j.abb.2011.11.014

13. Leshch, Y.; Jacobsen, A.; Thimm, A.; Thiem, J. Org. Lett. 2013, 15, 4948-4951. doi:10.1021/ol4021699

14. Schmidtke, C.; Kreuziger, A.-M.; Alpers, D.; Jacobsen, A.; Leshch, Y.; Eggers, R.; Kloust, H.; Tran, H.; Ostermann, J.; Schotten, T.; Thiem, J.; Thimm, J.; Weller, H. Langmuir 2013, 29, 12593-12600. doi:10.1021/la402826f

15. Levy, D. E.; Tang, C. The chemistry of C-glycosides; Pergamon: Oxford, 1995

16. Du, Y.; Linhardt, R. J.; Vlahov, I. R. Tetrahedron 1998, 54, 9913-9959. doi:10.1016/S0040-4020(98)00405-0

17. Jacobsen, A.; Thiem, J. Curr. Org. Chem. 2014, 18, 2833-2841. doi:10.2174/1385272819666141016215205

18. Montgomery, E. M.; Hudson, C. S. J. Am. Chem. Soc. 1939, 61, 1654-1658. doi:10.1021/ja01876a007 
19. Hricoviniova, Z.; Hricovini, M.; Petrusoa, M.; Matulova, M.; Petrus, L. Chem. Pap. 1998, 52, 238-243.

20. Sowden, J. C. J. Am. Chem. Soc. 1950, 72, 3325. doi:10.1021/ja01163a558

21. Schaffner, R.; Isbell, H. S. J. Org. Chem. 1962, 27, 3268-3270. doi:10.1021/jo01056a069

22. Cheng, J.; Fang, Z.; Li, S.; Zheng, B.; Jiang, Y. Carbohydr. Res. 2009, 344, 2093-2095. doi:10.1016/j.carres.2009.06.020

23. Kampf, A.; Dimant, E. Carbohydr. Res. 1974, 32, 380-382. doi:10.1016/S0008-6215(00)82116-3

24. Bessières, B.; Morin, C. J. Org. Chem. 2003, 68, 4100-4103. doi:10.1021/jo0342166

25. Liu, X.; Yin, Q.; Yin, J.; Chen, G.; Wang, X.; You, Q.-D.; Chen, Y.-L.; Xiong, B.; Shen, J. Eur. J. Org. Chem. 2014, 6150-6154. doi:10.1002/ejoc.201402757

26. Waschke, D.; Thimm, J.; Thiem, J. Org. Lett. 2011, 13, 3628-3631. doi:10.1021/ol2012764

27. Li, X.; Takahashi, H.; Ohtake, H.; Shiro, M.; Ikegami, S. Tetrahedron 2001, 57, 8053-8066. doi:10.1016/S0040-4020(01)00775-X

28. Northrup, A. B.; MacMillan, D. W. C. Science 2004, 305, 1752-1755. doi:10.1126/science.1101710

29. Timmer, M. S. M.; Adibekian, A.; Seeberger, P. H. Angew. Chem., Int. Ed. 2005, 44, 7605-7607. doi:10.1002/anie.200502742

30. Ahmed, M. M.; Berry, B. P.; Hunter, T. J.; Tomcik, D. J.; O'Doherty, G. A. Org. Lett. 2005, 7, 745-748. doi:10.1021/ol050044i

31. Adibekian, A.; Timmer, M. S. M.; Stallforth, P.; van Rijn, J.; Werz, D. B.; Seeberger, P. H. Chem. Commun. 2008, 3549-3551. doi:10.1039/B805159C

32. Stallforth, P.; Adibekian, A.; Seeberger, P. H. Org. Lett. 2008, 10, 1573-1576. doi:10.1021/ol800227b

33. Shan, M.; Xing, Y.; O'Doherty, G. A. J. Org. Chem. 2009, 74, 5961-5966. doi:10.1021/jo9009722

34. Ohara, T.; Adibekian, A.; Esposito, D.; Stallforth, P.; Seeberger, P. H. Chem. Commun. 2010, 46, 4106-4108. doi:10.1039/c000784f

35. Calin, O.; Pragani, R.; Seeberger, P. H. J. Org. Chem. 2012, 77, 870-877. doi:10.1021/jo201883k

36. Babu, R. S.; Chen, Q.; Kang, S.-W.; Zhou, M.; O'Doherty, G. A. J. Am. Chem. Soc. 2012, 134, 11952-11955. doi:10.1021/ja305321e

37. Gati, W.; Rammah, M. M.; Rammah, M. B.; Couty, F.; Evano, G. J. Am. Chem. Soc. 2012, 134, 9078-9081. doi:10.1021/ja303002a

38. Mlynarski, J.; Gut, B. Chem. Soc. Rev. 2012, 41, 587-596. doi:10.1039/C1CS15144D

39. Wang, H.-Y.; Yang, K.; Yin, D.; Liu, C.; Glazier, D. A.; Tang, W. Org. Lett. 2015, 17, 5272-5275. doi:10.1021/acs.orglett.5b02641

40. van Delft, F. L.; Rob, A.; Valentijn, P. M.; van der Marel, G. A.; van Boom, J. H. J. Carbohydr. Chem. 1999, 18, 165-190. doi:10.1080/07328309908543989

41. Grindley, T. B. Adv. Carbohydr. Chem. Biochem. 1998, 53, 17-142. doi:10.1016/S0065-2318(08)60043-8

42. Suri, J. T.; Mitsumori, S.; Albertshofer, K.; Tanaka, F.; Barbas, C. F., III. J. Org. Chem. 2006, 71, 3822-3828. doi:10.1021/jo0602017

43. Grondal, C.; Enders, D. Tetrahedron 2006, 62, 329-337. doi:10.1016/j.tet.2005.09.060

44. Bahmanyar, S.; Houk, K. N.; Martin, H. J.; List, B. J. Am. Chem. Soc. 2003, 125, 2475-2479. doi:10.1021/ja028812d

45. Hoang, L.; Bahmanyar, S.; Houk, K. N.; List, B. J. Am. Chem. Soc. 2003, 125, 16-17. doi:10.1021/ja028634o

46. Corey, E. J.; Erickson, B. W. J. Org. Chem. 1971, 36, 3553-3560. doi:10.1021/jo00822a019
47. Crich, D.; de la Mora, M. A.; Cruz, R. Tetrahedron 2002, 58, 35-44. doi:10.1016/S0040-4020(01)01087-0

\section{License and Terms}

This is an Open Access article under the terms of the Creative Commons Attribution License (http://creativecommons.org/licenses/by/4.0), which permits unrestricted use, distribution, and reproduction in any medium, provided the original work is properly cited.

The license is subject to the Beilstein Journal of Organic Chemistry terms and conditions:

(http://www.beilstein-journals.org/bjoc)

The definitive version of this article is the electronic one which can be found at: doi:10.3762/bjoc. 13.79 